\title{
Estimating volatility clustering and variance risk premium effects on bank default indicators
}

\author{
Turalay Kenc ${ }^{1,2}$ (D) Emrah Ismail Cevik ${ }^{3}$
}

Accepted: 26 March 2021 / Published online: 27 April 2021

(C) The Author(s), under exclusive licence to Springer Science+Business Media, LLC, part of Springer Nature 2021

\begin{abstract}
Default risk increases substantially during financial stress times due to mainly the two reasons: volatility clustering and investors' desire to protect themselves from such increases in volatility. It manifested in the aftermath of the Global Financial Crisis of 2008-2009 with unpleasant outcomes of many bankruptcies and severe financial distress. To account for these features, we adapted the structural credit risk approach to include both time-varying (return) volatility and risk premium about the return volatility itself. By applying the model to US banks, we obtain better bank default indicators in comparison to the benchmark models.
\end{abstract}

Keywords Default risk · Structural credit risk - GARCH option pricing · Banking · Variance risk premiums

JEL Classification $\mathrm{G} 01 \cdot \mathrm{G} 21 \cdot \mathrm{G} 28$

\section{Introduction}

This paper provides default risk indicators for large US banks by adding volatility clustering and variance risk premium features into the widely used structural credit risk approach. Our motivation stems from the fact that default risk increases substantially during financial stress times due to mainly the two reasons: volatility clustering and investors' willingness to protect themselves from such increases in volatility. Experiences from such episodes like the Global Financial Crisis (GFC) of 2007-2009 and the Covid-19 pandemic show that the volatility of asset prices get heightened, and in turn, leads to increases in the default

Turalay Kenc

Turalay.Kenc@gmail.com; tkenc@etu.edu.tr

Emrah Ismail Cevik

eicevik@nku.edu.tr

1 CERF, Cambridge Judge Business School, University of Cambridge, Trumpington Street, Cambridge CB2 1AG, UK

2 Present Address: TOBB University of Economics and Technology, Sogutozu Cd. No:43, 06510 Çankaya, Ankara, Turkey

3 Tekirdag Namik Kemal University, Tekirdağ, Turkey 
probability. For example, in the aftermath of the GFC, many US banks experienced severe financial distress and even bankruptcies. More precisely, banks default on their debt if their asset value does not cover the liabilities at the time of the repayment. Investors' appetite for risk aversion to the volatility of such increases in volatility further reinforces this process. This variance risk premium fosters default risk by adding on declines in asset prices.

In market downturns, the volatility clustering and variance risk premiums phenomena coupled with fundamental weaknesses in financial balance sheets such as high leverage ratios and asset-liability mismatches often lead to financial distresses and even bankruptcies in severe cases. Indeed, the Federal Deposit Insurance Corporation (FDIC) closed 465 failed banks from 2008 to 2012. In contrast, in the five years prior to 2008, only 10 banks failed. The Federal Reserve System (the FED) provided liquidity support for the remaining financially distressed banks. Such a high-level bank failure reflects the fact that the special nature of bank assets due to its limited upside gains leads to volatile bank equity returns and hence higher default risk (see Nagel and Purnanandam 2019). Simultaneous failures of banks in the US have raised doubts on risk management practices worldwide and provided strong motivation for monitoring the default risk of financial institutions to prevent financial crises in advance. Such conditions evidently necessitate a reliable model of default risk that amply captures the impact of heightened volatility episodes on default measures.

The structural credit risk approach developed in Merton (1974) is a benchmark in default risk estimation because it takes asset returns, volatility, leverage, and maturity into accounts in a forward looking-way. Precisely, the model is used to extract asset values hence its asset returns and volatility from equity prices by exploiting the claim that the call option written on the firm asset value is equal to the firm equity value. Market information on their stock prices is then used in a forward-looking way to estimate the implied default probabilities for banks. For example, a decline in the stock price of a firm, ceteris paribus, corresponds to an increase in the default probability of that bank. The size of this impact depends on its leverage ratio, return volatility level and risk premium about the return volatility itself. A large body of literature (Crosbie and Bohn 2003; Hillegeist et al. 2004; Bharath and Shumway 2008; Agarwal and Taffler 2008; Milne 2014; Leland 2015; Jessen and Lando 2015; Afik et al. 2016; Nagel and Purnanandam 2019; Imerman 2020) ${ }^{1}$ finds that the Merton model is empirically a strong predictor of default. However, the success of the Merton model is in ranking firms' default probabilities. Otherwise, it is notoriously known to produce default probabilities that are too low.

To this end, the literature has incorporated new features into the Merton model such as jumps in asset values, stochastic volatility, endogenous default. Several papers (Jessen and Lando 2015; Engle and Siriwardane 2018) have highlighted the power of volatility dynamics in explaining default probability. To capture the volatility dynamics observed during market downturns adequately, we introduce time-varying volatility via an appropriate GARCH model. Volatility in stock markets tends to breed future ones. In market downturns, this phenomenon becomes even more pronounced as markets often produce heightened market volatility. ${ }^{2}$ We adopted the GARCH model of Heston and Nandi (2000) (HN-GARCH). This model has desirable features: among others (1) it captures asymmetry

\footnotetext{
1 Reduced-form models (Duffie et al. 2007; Campbell et al. 2011) also widely use the Merton model's default indicator the distance-to-default as an explanatory variable.

2 There is overwhelming empirical evidence that GARCH models dominate the benchmark constant volatility Black-Scholes model achieving significant overall improvements in pricing performance. See Lehar et al. (2002), Hsieh and Ritchken (2005) and Christoffersen et al. (2013b).
} 
in the response of volatility to positive versus negative return shocks, which is commonly referred to as the leverage effect; and (2) it provides a closed-form option pricing formula. The HN-GARCH model has wide applications in the options pricing literature (Christoffersen et al. 2013b; Kenc et al. 2021, and references therein).

However, a vast body of literature starting with (Bakshi and Kapadia 2003; Carr and Wu 2009; Bollerslev et al. 2009) has increasingly recognized that the presence of variance risk premiums improves the model fit of the option pricing frameworks. Indeed, the literature provide a great deal of evidence on the existence of negative and economically large variance risk premiums in equity markets and other financial markets. More importantly, the work of Wang et al. (2013) finds that the variance risk premium has a prominent explanatory power for credit risk spreads. As a result, many papers have extended either the HN-GARCH model or the stochastic volatility of Heston (1993) to variance risk premiums, applying it to several financial markets including equity, bond, credit risk, commodity and foreign currency (Christoffersen et al. 2013a; Hao and Zhang 2013; Wang et al. 2013; Bu and Liao 2014; Byun et al. 2015; Babaoglu et al. 2018; Della Corte et al. 2016; Choi et al. 2017; Dew-Becker et al. 2017; Prokopczuk et al. 2017). We closely follow Christoffersen et al. (2013a) to incorporate variance risk premiums into the HN-GARCH framework. They show that variance risk premiums scale-up conditional variance values and hence address the low default probabilities deficiency problem of the Merton model.

This paper draws on the following strands of the literature. First of all, it is related to research on the insolvency of financial institutions more precisely on the structural models of default risk inspired by the seminal work of Merton (1974). In the area of default risks in the banking sector (Lehar 2005; Gropp et al. 2006; Harada et al. 2010; Câmara et al. 2012; Milne 2014) applied this benchmark Merton model. The next related literature is the Merton model with volatility clustering. Like the papers by Balachandran et al. (2010), Culp et al. (2018) and Engle and Siriwardane (2018) our paper is also capable of capturing volatility clustering. Engle and Siriwardane (2018) develops a structural GARCH model by combining the Merton structural credit risk framework and the Glosten et al. (1993) GARCH specification to capture equity volatility asymmetry-the well-known negative correlation between equity returns and equity volatility. Culp et al. (2018) introduces a novel, model-free benchmarking methodology to the empirical Merton model. However, these papers are quite different from the standard KMV-Merton literature in terms of the underlying model and their applications. In this regard, our paper strictly belongs to the KMV-Merton strand of the literature and hence generates comparable results. Balachandran et al. (2010) analyze specifically the effects of executive compensation on extreme risk. Finally, Du et al. (2019) also applies the time-varying asset volatility to address the credit spread puzzle while Jessen and Lando (2015) highlights the importance of "a volatility adjustment of the distance-to-default measure" in order to significantly improve default forecasting. Finally, our paper is related to the variance risk premium literature. We mentioned many of the related papers on the variance risk premium in the previous paragraph. None of these papers consider the estimation of default risks for neither banks nor nonfinancial firms.

Our structural default risk model with GARCH and VRP features has significantly improved the existing results of the literature as it generates statistically significant results in predicting default events and forecasting default probabilities. In all performance measures that we apply, the predictive power of the model with volatility clustering and variance risk premium is higher than the benchmark the KMV-Merton model without them. For example, our ROC (Receiver Operating Characteristic) and CAP (Cumulative Accuracy Profile) analysis show that the HN-GARCH-VRP model produces higher rates of hits (true positives) for 
any given rate of false alarms compared to the other two models. Similarly, markedly better performances are also recorded by the GARCH-VRP model over the other two models in terms of hazard model probabilities with respect to default risk indicators.

The paper proceeds as follows. In Sect. 2 we discuss the three structural default risk models used in this paper, namely the benchmark Merton model, the HN-GARCH extended Merton model and the HN-GARCH and VRP extended Merton model. In Sects. 3 and 4, we describe implementation of the model, i.e., the transformed-data maximum likelihood method developed by Duan (1994, 2000) and data. Empirical findings of the paper are in Sect. 5, followed by conclusion in Sect. 6 .

\section{Structural default models}

In this section, we start with the benchmark Merton model, which will be followed by the GARCH option pricing model used in this paper to estimate default probabilities.

\subsection{The benchmark merton model}

The Merton approach to structural default modelling is to assume that a company (a bank in our case) at time $t$ has a certain amount of (a single) zero-coupon debt that will become due at a future time $t+T$ and that this company defaults if the value of its assets $A$ is less than the promised debt repayment $K$ at time $t+T$. The probability of such a default, assuming $K$ does not change until $t+T$, is given by

$$
P_{\text {def }, t}=\operatorname{Prob}\left(A_{t+T} \leq K_{t} \mid \mathcal{F}_{t}\right)=\operatorname{Prob}\left(\ln \left(A_{t+T}\right) \leq \ln \left(K_{t}\right) \mid \mathcal{F}_{t}\right)
$$

where $\mathcal{F}_{t}$ denotes the information available at time $t$. To proceed, the approach requires a stochastic process under the physical probability measure $(\mathbf{P})$ to specify the dynamics of $A$ :

$$
d A_{t}=\mu_{A} A_{t} d t+\sigma_{A} A_{t} d W_{t}
$$

where $\mu_{A}$ is the expected continuously compounded return on $A, \sigma_{A}$ is the volatility of asset returns and $d W$ is a standard Wiener process. Key parameters $\mu_{A}$ and $\sigma_{A}$ of this process are constant over the life of the firm. Eq. (2) is also written as:

$$
\ln A_{t+T}=\ln A_{t}+\left[\mu_{A}-\frac{1}{2} \sigma_{A}^{2}\right] T+\sigma_{A} \sqrt{T} \varepsilon_{t+T},
$$

where

$$
\varepsilon_{t+T}=\frac{W_{t+T}-W_{t}}{\sqrt{T}} \text { and } \varepsilon_{t+T} \sim N(0,1)
$$


Substituting this last Eq. (3) into Eq. (1) yields the following new expression for the default probability $^{3}$

$$
\begin{gathered}
P_{d e f}^{M}=N\left(\ln A_{t}-\ln (K)+\left[\mu_{A}-\frac{1}{2} \sigma_{A}^{2}\right] T+\sigma_{A} \sqrt{T} \varepsilon_{t+T} \leq 0\right), \\
P_{d e f}^{M}=N\left(-D D \geq \varepsilon_{t+T}\right),
\end{gathered}
$$

where $D D$ represents the distance to default, which is defined as

$$
D D=\frac{\ln (A / K)+\left[\mu_{A}-\frac{1}{2} \sigma_{A}^{2}\right] T}{\sigma_{A} \sqrt{T}} .
$$

This roughly measures the number of standard deviations the firm's asset value would have to decrease in order to reach the default point $K .{ }^{4}$ In Eq. (5), we have three unknowns: $A$, $\mu_{A}$ and $\sigma_{A}$ which are estimated from equity data. The estimation procedure is based on the option pricing framework which relates equity values to asset values in this context. There exit several approaches in implementing this procedure. ${ }^{5}$ We will follow the (1) the transformed-data maximum likelihood method developed by Duan $(1994,2000)$.

\subsection{The Heston-Nandi GARCH option pricing model}

We follow Christoffersen et al. (2013b), among others, to specify the Heston-Nandi GARCH process as follows:

$$
\begin{gathered}
\ln A_{t}=\ln A_{t-1}+r+\left(\lambda-\frac{1}{2}\right) h_{t}+\sqrt{h_{t}} \varepsilon_{t}, \\
h_{t}=\beta_{0}+\beta_{1} h_{t-1}+\beta_{2}\left(\varepsilon_{t-1}-\gamma \sqrt{h_{t-1}}\right)^{2},
\end{gathered}
$$

where $r$ is the continuously compounded risk-free rate, $h_{t}$ is the conditional variance of the $\log$ return between $t-1$ and $t$ and $\varepsilon_{t}$ is a standard normal random variable. Moreover, $\beta_{1}$ is the autoregressive parameter and $\beta_{2}$ is related to the volatility of volatility, and thus kurtosis. The $\gamma$ parameter captures asymmetry in the response of volatility to positive versus negative return shocks, which is commonly referred to as the leverage effect. The persistence parameter is $\pi=\beta_{1}+\beta_{2} \gamma^{2}$. The term $r+\lambda h_{t}$ in Eq. (6) is the expected rate of return, implying that $\lambda h_{t}$ is the risk premium.

\footnotetext{
${ }^{3}$ As pointed out by Vassalou and Xing (2004) the theoretical distribution implied by the Merton model is the normal distribution. On the contrary, the KMV approach utilizes their own default database to derive an empirical distribution relating the distance-to-default to a default probability. In this regard, unlike the default probability calculated by KMV the probability measure in Eq. (4) may not correspond to the true probability of default in large samples.

${ }^{4} N(-D D)$ is then the corresponding implied probability of default and sometimes called the expected default frequency (or EDF).

${ }^{5}$ Duan (2012) discusses the widely-used four methods, namely (1) the market value proxy method, (2) the volatility restriction method, (3) the iterative method and (4) the transformed-data maximum likelihood method. For a similar discussion see also Jessen and Lando (2015).
} 


\subsection{Variance risk premia}

In the presence of variance risk premia we modify the stochastic processes for $A$ and $h$ as follows:

$$
\begin{gathered}
\ln \left(A_{t}\right)=\ln \left(A_{t-1}\right)+r-\frac{1}{2} h_{t}^{*}+\sqrt{h^{*}} \varepsilon_{t}^{*} \text { with } \varepsilon_{t}^{*} \sim N(0,1), \\
h_{t}^{*}=\beta_{0}^{*}+\beta_{1}^{*}\left(\varepsilon_{t-1}^{*}-\gamma^{*} \sqrt{h_{t-1}^{*}}\right)^{2}+\beta_{2} h_{t-1}^{*},
\end{gathered}
$$

where

$$
\begin{aligned}
h_{t}^{*} & =h_{t} /\left(1-2 \beta_{0} \xi\right) \\
\beta_{0}^{*} & =\beta_{0} /\left(1-2 \beta_{0} \xi\right) \\
\beta_{1}^{*} & =\beta_{1} /\left(1-2 \beta_{0} \xi\right) \\
\gamma^{*} & =\gamma-v \\
v & =-\left(\lambda-\frac{1}{2}+\gamma\right)\left(1-2 \beta_{0} \xi\right)+\gamma-\frac{1}{2},
\end{aligned}
$$

In the above equations, $\phi$ and $\xi$ are the pricing kernel parameters that determine the price of asset price risk and variance risk premium.

Equations (8) (or 6) and (9) (or 7) reveal that both the drift and diffusion terms of the asset value process are time-varying. Because of this heteroskedasticity, the unconditional distribution is fat-tailed. To ensure stationarity of the variance, it is required that the parameters satisfy $\beta_{1}\left(1+\gamma^{2}\right)+\beta_{2}<1$ under the basic GARCH and $\beta_{1}^{*}\left(1+\gamma^{* 2}\right)+\beta_{2}<1$ under the GARCH-VRP. The unconditional variances of the process under basic GARCH and GARCH-VRP are then given by $\beta_{0} /\left[1-\beta_{1}\left(1+\gamma^{2}\right)-\beta_{2}\right]$ and $\beta_{0}^{*} /\left[1-\beta_{1}^{*}\left(1+\gamma^{* 2}\right)-\beta_{2}^{*}\right]$, respectively. The GARCH process defined in Eqs. (8) (or 6) and (9) (or 7) reduces to the standard homoskedastic lognormal process of the Merton model if $\beta_{1}=0$ and $\beta_{2}=0$.

In other words, the Merton model is obtained as a special case. Note that in the above equations, the length of observation determines the time period of the terms $r$ and $h_{t}$. So, if the estimation interval is monthly, then, for example, $r_{t}$ is the monthly interest rate at time $t$.

Estimating default probabilities with GARCH using Eqs. (6)-(7) and Eqs. (8)-(9) when the variance risk premium is at present is not an easy task. There are two challenges: (1) obtaining expressions for $A_{t+T}$ and hence its drift and diffusion terms required in Eq. (6) or Eq. (8) and (2) backing out these unobservables ( $A$ and the related terms) from observable variables. To tackle these challenges, we utilize the basic and extended forms of the HN-GARCH option pricing model and the transformed-data maximum likelihood estimation (MLE) method developed by Duan (1995). We will explain the steps at some length below. Heston and Nandi (2000) obtained a closed-form solutions for the values of European type options written on the underlying assets that follow the GARCH model specified in Eqs. (6) and (7). Their derivation also includes an expression for the probability of the value of $A$ being greater than $K$ at the option expiry date $t+T$. Based on the risk-neutral process explained in Appendix 1, Heston and Nandi (2000) obtained a closed-form solution for European type options via Fourier inversion. The formula for a call option $C^{H N}$ with strike price $\mathrm{K}$ that expires at time $t+T$ is given by:

$$
C^{H N}\left(A_{t}, K, r, h_{t}, T\right)=A_{t} \mathrm{P}_{1}^{\mathrm{Q}, \mathrm{HN}}\left(r, h^{\mathrm{Q}}, .\right)-K e^{-r T} \mathrm{P}_{2}^{\mathrm{Q}, \mathrm{HN}}\left(r, h^{\mathrm{Q}}, .\right)
$$


where $\mathrm{P}_{1}^{\mathrm{Q}, \mathrm{HN}}$ and $\mathrm{P}_{2}^{\mathrm{Q}, \mathrm{HN}}$ are the probability terms corresponding to the Black-Scholes-Merton model's usual terms $N\left(d_{1}\right)$ and $N\left(d_{2}\right)$ :

$$
\begin{gathered}
\mathrm{P}_{1}^{\mathrm{Q}, \mathrm{HN}}\left(r, h^{\mathrm{Q}}, .\right)=\frac{1}{2}+\frac{e^{-r T}}{A_{t} \pi} \int_{0}^{\infty} \operatorname{Re}\left[\frac{K^{-i \phi} f^{*}(t, T ; i \phi+1)}{i \phi f(1)}\right] d \phi, \\
\mathrm{P}_{2}^{\mathrm{Q}, \mathrm{HN}}\left(r, h^{\mathrm{Q}}, .\right)=\frac{1}{2}+\frac{1}{\pi} \int_{0}^{\infty} \operatorname{Re}\left[\frac{K^{-i \phi} f^{*}(t, T ; i \phi)}{i \phi}\right] d \phi,
\end{gathered}
$$

where $f^{*}(t, T ; i \phi)$ is the conditional characteristic function of the logarithm of the spot price under the risk-neutral measure (see Appendix 1). Incorporating variance risk premia into the $\mathrm{HN}-\mathrm{GARCH}$ option pricing framework is straight forward since we only require to use the scaled values of $h_{t}^{*}, \beta_{0}^{*}, \beta_{1}^{*}$ and $\gamma^{*}$ :

$$
\begin{gathered}
C^{H N^{*}}\left(A_{t}, K, r, h_{t}^{*}, T\right)=A_{t} \mathrm{P}_{1}^{\mathrm{Q}, \mathrm{HN}}\left(r, h^{Q^{*}}, .\right)-K e^{-r T} \mathrm{P}_{2}^{\mathrm{Q}, \mathrm{HN}^{*}}\left(r, h^{Q^{*}}, .\right) \\
\mathrm{P}_{1}^{\mathrm{Q}, \mathrm{HN}^{*}}\left(r, h^{Q^{*}}, .\right)=\frac{1}{2}+\frac{e^{-r T}}{A_{t} \pi} \int_{0}^{\infty} \operatorname{Re}\left[\frac{K^{-i \phi} f^{*}(t, T ; i \phi+1)}{i \phi f(1)}\right] d \phi, \\
\mathrm{P}_{2}^{\mathrm{Q}, \mathrm{HN}^{*}}\left(r, h^{Q^{*}}, .\right)=\frac{1}{2}+\frac{1}{\pi} \int_{0}^{\infty} \operatorname{Re}\left[\frac{K^{-i \phi} f^{*}(t, T ; i \phi)}{i \phi}\right] d \phi,
\end{gathered}
$$

Having written down the Heston-Nandi GARCH option valuation framework with and without VRP, we can now rewrite the probability of the default expression in (1) in a more explicit form:

$$
\begin{gathered}
P_{d e f, t}^{H N^{*}}=1-\mathrm{P}_{2}^{\mathrm{P}}\left(r+\lambda h^{\mathrm{P}}, h^{\mathrm{P}}, A^{H N}, .\right) \\
P_{d e f, t}^{H N^{*}}=1-\mathrm{P}_{2}^{\mathrm{P}}\left(r+\lambda h^{\mathrm{P}}, h^{\mathrm{P}}, A^{H N^{*}}, .\right)
\end{gathered}
$$

Note that the default probabilities in equations in (14) and (15) are physical measures as required. Hence we now discount future cash flows at $r+\lambda h_{t}$ rather than only at $r$. Also, asset values $A_{t}$ and variance $h_{t}$ are simulated over time using Eqs. (6) and (7) under the HN-GARCH model and Eqs. (8) and (9) under the HN-GARCH-VRP. Comparing the default probability indicators in Eqs. (5) and (14) together with Eqs. (11a)-(11b) reveals that the latter is much more complicated as it takes into account a rich set of volatility dynamics with and without VRP. The rich volatility dynamics stemming from the GARCH specification captures the volatility clustering effect. Large changes in volatility tend to be followed by large ones. This heightened volatility then directly increases the default probability as under high $h_{t}$ it is more likely that the asset value may be less than the debt value compared to when $h_{t}$ is low. There is also an indirect effect on default which stems from the fact that the increased volatility pushes up the option (equity) value and hence the implied asset value, lowering default probability. To see which effect will dominate, we can use the distance-to-default expressions in Eqs. (5) and (4). The direct effect via $\sqrt{h_{t}}$ appears in the denominator. Finally, the GARCH process defined in Eqs. (6) and (7) reduces to the standard homoskedastic lognormal process of the Merton model if $\beta_{0}=0$ and $\beta_{1}=0$. As for the impact of the GARCH with VRP model, we note that the risk-neutral variance, persistence, 
and volatility of variance in this new model differ from their physical counterparts. Empirical restrictions on the underlying parameters imply that their values are larger than those of the physical ones. This in turn increases the option (equity) value, requiring lower values of bank assets in the backing out process. Precisely, we calibrate the option value to the equity value via the asset value as it is the underlying asset for the option. The lower is the asset value, the higher is the probability of default. Hence, default probability under our GARCH with VRP model will be larger than the model without VRP.

\section{Implementation of the extended Merton model}

In this section, we explain only the implementation of the Merton model with HN-GARCH specification and VRP. In fact, the other two methods, namely the Merton method and the HN-GARCH extended Merton model are simply the special cases of the model with both GARCH and VRP features. Given the time-varying volatility feature of our model, we think that the most appropriate method for estimating the HN-GARCH based default probability measure is the transformed-data MLE method developed by Duan (1994, 2000). We will now explain the steps below.

If we had data on assets in order to estimate the parameters of the $A_{t}$ process, we could have maximized the following log-likelihood function:

$$
\begin{aligned}
\ln L(A ; \Theta) & =-\frac{1}{2} \sum_{i=1}^{n}\left\{\ln \left(h_{i}\right)+\left[\ln \left(A_{i} / A_{i-1}\right)-r_{i}-\left(\lambda-\frac{1}{2}\right) h_{i}\right]^{2} / h_{i}\right\} \\
h_{i} & =\beta_{0}+\beta_{1} h_{i-1}+\beta_{2}\left(\varepsilon_{i-1}-\gamma \sqrt{h_{i-1}}\right)^{2},
\end{aligned}
$$

where $n$ is the number of observations and $\Theta=\left\{\beta_{0}, \beta_{1}, \beta_{2}, \gamma, \lambda\right\}$. Since we do not observe the value of assets, we back them out from the call option price equation in (12). The contingent claims approach suggested that the call option written on the value of assets as explained above is equal to the value of the equity:

$$
E_{t}=g\left(A_{t}, K, r, h_{t}, T\right)=A_{t} \mathrm{P}_{1}^{\mathrm{Q}, \mathrm{HN}^{*}}\left(r, h^{\mathrm{Q}, \mathrm{HN}^{*}}, .\right)-K e^{-r T} \mathrm{P}_{2}^{\mathrm{Q}, \mathrm{HN}^{*}}\left(r, h^{\mathrm{Q}, \mathrm{HN}^{*}}, .\right)
$$

Hence, we write $A_{t}=g^{-1}(E, K, r, h, T)$ with $T=\Delta t \times n, \Delta t$ being the length of time interval. Duan $(1994,2000)$ recognizes that the density of the equity value can be obtained as

$$
f(E)=\frac{f(A)}{\frac{\partial g(A, K, r, h, T)}{\partial A}}
$$

Plugging the resulting expression into the above log-likelihood function in (16) yields the following log-likelihood function on the observed equity data:

$$
\begin{aligned}
\ln L(E ; \Theta)=- & \frac{1}{2} \sum_{i=1}^{n}\left\{\ln \left(h_{i}\right)+\left[\ln \left(g^{-1}\left(E_{i}\right) / g^{-1}\left(E_{i-1}\right)\right)-r_{i}-\left(\lambda-\frac{1}{2}\right) h_{i}\right]^{2} / h_{i}\right\} \\
& -\sum_{i=1}^{n} \mathbf{P}_{1}\left(g^{-1}\left(E_{i-1}\right)\right) .
\end{aligned}
$$

To make the parameter estimates consistent with the observed long-term variance in MLE under the physical measure, we used the relation $\beta_{0}=h(1-\psi)-1$, where $h$ is the 
unconditional variance under the physical measure, calculated directly from preceding daily return series and $\psi$ is the autoregressive term.

The final step is to plug the asset values into the default probability equation in (14) and to estimate the default probability of each bank in the sample. We convert these daily default probabilities into monthly data by using the maximum value for each month.

\section{Data}

Our sample consists of large U.S. commercial banks based on their total assets. We choose banks with total assets exceeding \$1 billion as of the end of 2006. There were 138 banks from the sample of 159 that met the criterion after eliminating 21 banks due to data unavailability, implying a share of $73 \%$ in the commercial banking sector. To classify a bank as distressed, we apply the following three criteria adopted from the work of Câmara et al. (2012): ${ }^{6}$

1. The bank failed or got acquired in 2008-2009. ${ }^{7}$

2. The firm has a below-investment-grade credit rating by at least one of the three big rating agency firms, namely S\&P, Moodys and Fitch during 2008-2009.

3. The stock price dropped below $\$ 5.00$ per share from a previous high and remained below this threshold, and the bank had suspended dividend payments.

Upon a careful examination of the sample of 138 banks for the criteria during the period 2008-2009, we classified 42 financial firms as distressed, leaving the remaining 96 as sound entities. Table 4 in Appendix 1 presents the stress status of each sample bank. The data set includes both accounting variables such as short-term debt, long-term debt, the number of shares outstanding and financial variables such as daily stock prices and the risk-free rate from 2000-2013. All data come from DataStream except for the risk-free rate and capital adequacy ratio, whose source is Federal Reserve Economic Data (FRED). The frequency of the accounting data is yearly; hence to obtain daily values following the work of Balachandran et al. (2010) we employ the cubic spline method. Since default takes place only at the maturity of debt, implementing the Merton type of structural default risk models requires the conversion of debt maturities into the face value of a single short-term one. The commonly adopted approach (Vassalou and Xing 2004; Bharath and Shumway 2008) is to take the total of short-term debt plus half of the long-term term debt. However, in the classification of short-term liabilities, the banking sector requires further refinement. As argued by Harada et al. (2010), maturity is not economically relevant for banks because, in the case of a bank run, the depositors tend to withdraw even if the maturity of the deposit is long-term. Like Harada et al. (2010) and Saldias (2013), we also calculate the short-term liabilities as of the sum of the total deposit and short-term debt. As for equity values and risk-free rates, we obtain them from the daily stock prices for each bank and the one year T-bill rate, respectively.

\footnotetext{
${ }^{6}$ The default events for each bank are obtained from the Federal Deposit Insurance Corporation (https:// www.fdic.gov/bank/individual/failed/banklist.html).

${ }^{7}$ Although the GFC started in 2007, bank failures and acquisitions took place during this period due to the GFC.
} 


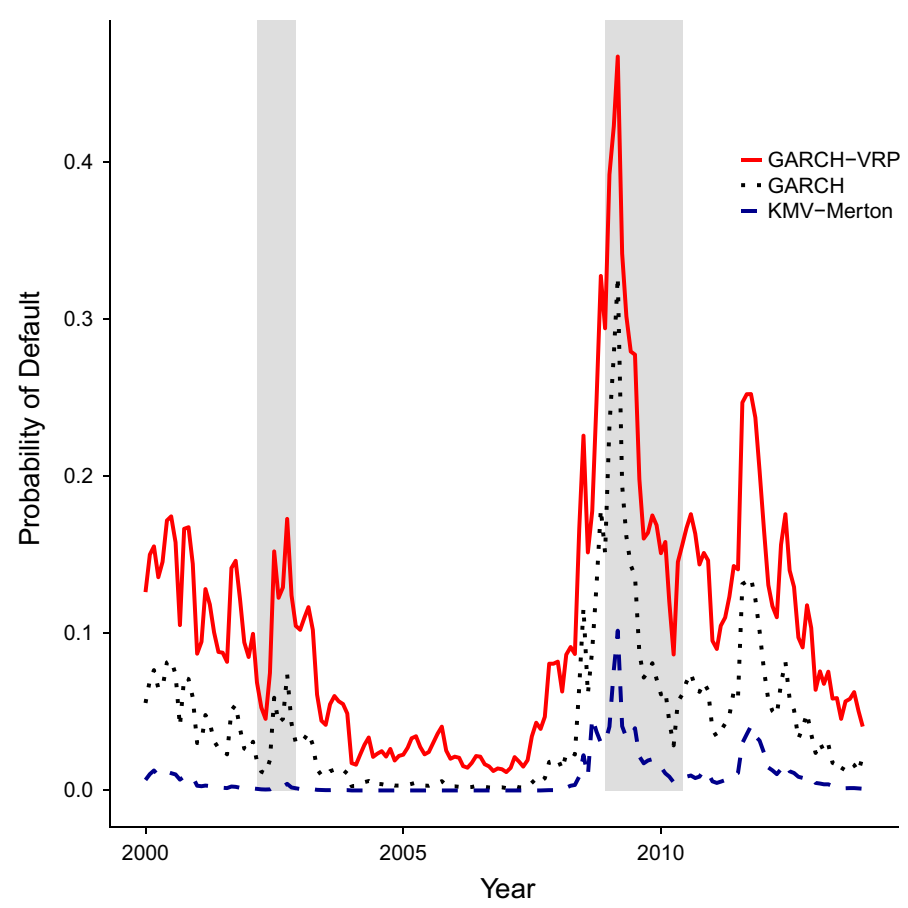

Fig. 1 Probability of default this figure plots the average of default probabilities of 138 large US banks over the period 2000-2013. The probability of default for each bank for our three models is computed using Eqs. (4), (14) and (15), respectively

\section{Empirical results}

The empirical work starts with the estimation of the parameters of the three alternative models, namely (1) the KMV-Merton model, (2) the GARCH extended Merton model and (3) the GARCH and VRP extended Merton model for which we use the Transformed Data Maximum Likelihood Method by Duan (1994, 2000). The critical step in calculating option prices with a variance risk premium is to estimate the variance risk premium parameter $(\xi)$. We take its value from the empirical work when pricing variance risk premia. In fact, in this paper, as in Christoffersen et al. (2013a) we take 117,438 for the variance risk premium parameter $\xi .{ }^{8}$ Note that as demonstrated in Christoffersen et al. (2013a) although the variance risk premium parameter is taken as a constant value, in the presence of the time-varying GARCH volatility even this constant parameter setting leads to time-varying variance-risk premia.

We first present descriptive statistics for estimated average capital default probabilities for 138 banks within the sample. Table 1 presents the mean, median, maximum and minimum values, the standard deviation of default probabilities that are obtained under

\footnotetext{
${ }^{8}$ In recent years, there has been a great interest in incorporating variance risk premia into financial valuation models. Financial economists use different methods to estimate this premium, ranging from a joint estimation of variance risk premia and return-risk premium approach to a sequential approach. See Babaoglu et al. (2018), Christoffersen et al. (2013a) and Papantonis (2016) among others.
} 
Table 1 Descriptive statistics

\begin{tabular}{llll}
\hline & KMV-Merton & GARCH & GARCH-VRP \\
\hline Mean & 0.008 & 0.043 & 0.105 \\
Median & 0.002 & 0.030 & 0.091 \\
Maximum & 0.101 & 0.327 & 0.467 \\
Minimum & 0.000 & 0.001 & 0.011 \\
Std. Dev. & 0.013 & 0.050 & 0.083 \\
Spearman rank correlation & & \\
KMV-Merton & 1.000 & & \\
GARCH & $0.992 * * *$ & 1.000 & \\
GARCH-VRP & $0.943 * * *$ & $0.958 * * *$ & 1.000 \\
***, ** and * indicate statistical significance at 1, 5 and 10 percent, \\
respectively
\end{tabular}

the three models: (1) the KMV-Merton model, (2) the GARCH extended Merton model and (3) the GARCH with VRP extended Merton model. The main message of this table is that the GARCH option pricing model with variance risk premium (denoted by GARCHVRP) yields both higher mean, median and maximum default probabilities compared to the KMV-Merton model and the GARCH option pricing model without variance risk premium. Similarly, without variance risk premia the standard GARCH option pricing model still produces higher mean and maximum default probabilities compared to the KMV-Merton model in which the volatility specification is atemporal. Figure 1 plots the time profile of the average estimated default probabilities across 138 US banks with the shaded areas representing NBER recessions in the US. A prominent feature of Fig. 1 is the relatively high default probabilities implied by both HN-GARCH option pricing models with and without variance risk premia at the beginning of the sample as well as during the Global Financial Crisis of 2008-2009. As in Table 1, Fig. 1 also reveals that throughout the sample the model with variance risk premia generates higher default probabilities compared to the other two models.

\subsection{Measuring model accuracy}

In order to identify the statistical importance of these results, we have employed a number of statistical performance measures and tests that are typical in the related literature. These are the Spearman (correlation coefficient) test, the Receiver Operating Characteristics (ROC) analysis and the hazard model.

We first employ the Receiver Operating Curve (ROC) that is the most widely accepted technique used in practice to determine the ability of a model to predict actual defaults over a 3-year horizon. The ROC is a graph of true positive rates (TPR) and false positive rates (FPR) where TPR can be calculated as the ratio of the number of distressed firms classified as high risk to the total number of distressed firms and the FPR is called the false alarm rate and is calculated as the ratio of the number of non-failed firms classified as high risk to the total number of solvent firms. Note that the area under the curve (AUC) is that of a perfect model and the 45-degree line is due to a random classification. The AUC is between 0 and 1 and the AUC of a random assignment is 0.5. Accordingly, the AUC of the "perfect" model is 1 . On the other hand, when the test includes non-failed firms with low default probability, it is advantageous to employ a partial AUC (pAUC) test that focuses 
Table 2 Area under the ROC curves

\begin{tabular}{lccclc}
\hline & ROC & $\chi^{2}$-stat & $p$ value & pAUC (0.25) & $p$ value \\
\hline KMV-Merton & 0.950 & 4.59 & {$[0.003]$} & 0.211 & {$[0.041]$} \\
GARCH & 0.957 & 2.79 & {$[0.094]$} & 0.218 & {$[0.054]$} \\
GARCH-VRP & 0.988 & & & 0.236 & \\
\hline
\end{tabular}

$\chi^{2}$-stat gives the test statistic where the null hypothesis indicates that AUC (pAUC) value for GARCH-VR model is not different from the AUC value of the KMV-Merton and GARCH models and $p$ values show probability of rejecting the null hypothesis

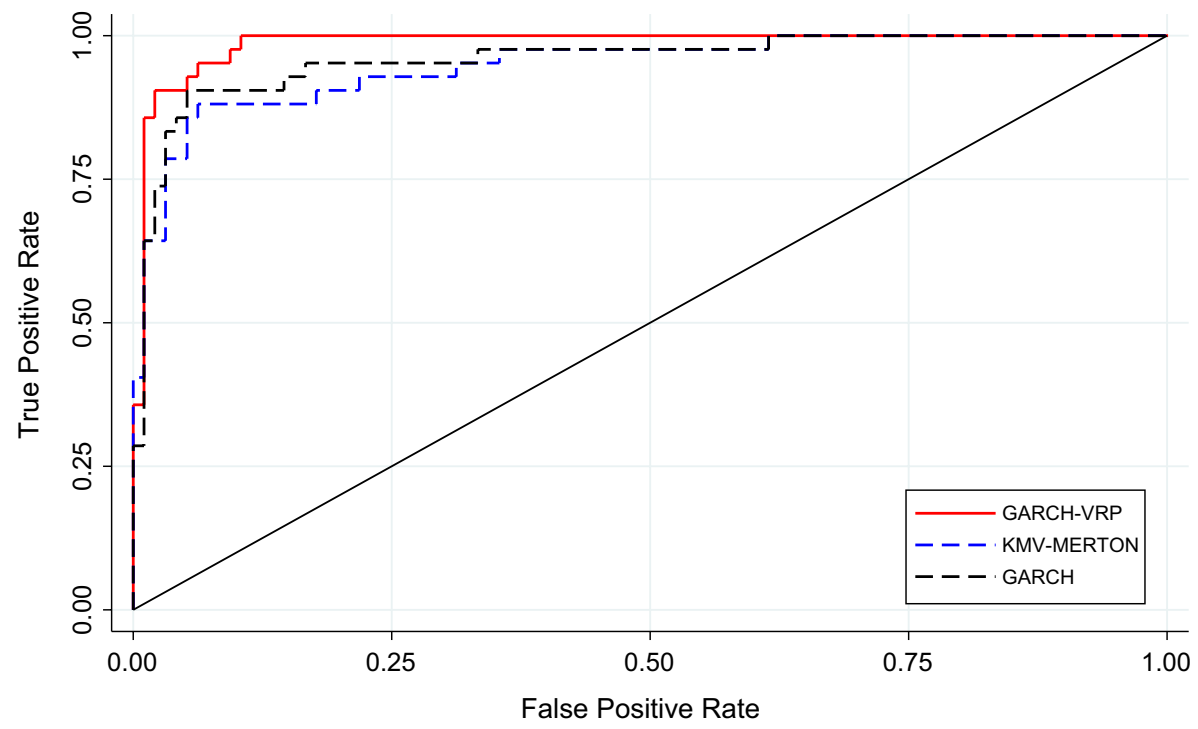

Fig. 2 ROC curves for KMV-Merton, GARCH and GARCH with variance risk premia models

on the interval of low FPR. Therefore we also calculate the pAUC for 0.25 that would be informative for investors, lenders, or regulators then the entire curve. To construct the ROC curve, we rank banks from high-risk to low-risk according to maximum default probabilities for the 2007-2009 period. The ROC curves are given in Fig. 2 and the AUC and pAUC values for the respective ROC curves in Table 2. Results in Fig. 2 and Table 2 indicate that the GARCH-VRP model outperforms the KMV-Merton and GARCH models in classifying all firms into distressed or non-distressed states as the largest AUC value is obtained from the GARCH-VRP model (0.988). Moreover, this score is statistically higher than the KMVMerton and GARCH models at the $1 \%$ and $10 \%$ levels respectively. The pAUC values for the $F P R \leq 0.25$ interval yields similar results in that the largest value is obtained from GARCH-VRP model and this is statistically higher than the Merton and GARCH models 
Table 3 Hazard model results

\begin{tabular}{llll}
\hline Dependent variable: duration (in months) until fail & \\
\hline Variables & Model 1 & Model 2 & Model 3 \\
\hline -DD GARCH-VRP & $6.603 * * *$ & - & - \\
-DD GARCH & - & $3.431 * * *$ & - \\
-DD KMV-MERTON & - & - & $1.741 * * *$ \\
log (K) & $1.244 * *$ & $1.279 * *$ & $1.189 * *$ \\
Excess & 1.150 & 1.270 & 1.072 \\
Number of observations & 21036 & 21036 & 21036 \\
Number of banks & 138 & 138 & 138 \\
Number of failures & 42 & 42 & 42 \\
Wald $\chi^{2}$ & $73.78[0.000]$ & $65.80[0.000]$ & $62.93[0.000]$ \\
Time at risk & 21036 & 21036 & 21036 \\
Zero slope test & $6.34[0.09]$ & $6.48[0.090]$ & $6.56[0.0875]$ \\
\hline
\end{tabular}

Models 1, 2 and 3 denotes the GARCH-VRP, GARCH and KMVMerton model, respectively. The distance-to-default measure (DD) for the KMV-Merton model is computed from Eq. (5). For the HNGARCH model the $D D$ formula is obtained by taking the normal inverse of Eq. (11b) (i.e., $-N^{-1}\left(P_{2}^{H N}\right)$ and for the GARCH-VRP model it is the normal inverse of Eq. (13b). *** and $* *$ indicates statistically significant correlation at the $1 \%$ and $5 \%$ level

at the $5 \%$ and $10 \%$ levels respectively. ${ }^{9}$ These results suggest that our credit risk model provides substantial information about future defaults.

Following Bharath and Shumway (2008), we apply the survival analysis to assess model accuracy via the Cox proportional hazard model. ${ }^{10}$ A popular survival analysis model, the Cox proportional hazard model uses the hazard rate that can be defined as the risk of bank failure where the bank has survived up to a specific time. The hazard indicates the expected number of bank failures per unit of time. Hence, the model allows us not only to use the level of a default indicator at a certain point in time but also how long the default indicator remains at this level. The Cox proportional hazard model can be written as follows:

$$
h r(t, D I, X)=h r_{0}(t) e^{\beta_{1}(-D D)+\beta_{2} X}
$$

where $h r(t, D I, X)$ is the proportional hazard function, $h r_{0}(t)$ is the baseline hazard rate and $D D$ is the distance to default ${ }^{11}$ and $X$ is the control variables such as excess returns (excess) and the face value of debt $(\mathrm{K})$. The model parameters can be estimated by using the following partial log-likelihood function:

\footnotetext{
${ }^{9}$ We also estimate the pAUC values for the $F P R \leq 0.1$ interval and the largest value is obtained from GARCH-VRP model and this found to be statistically higher than the Merton and GARCH models at the $10 \%$ level.

10 Gropp et al. (2006); Gupta et al. (2015) also used the hazard model to predict the failure of firms.

11 In models with HN-GARCH specifications we do not have explicit DD expressions. We therefore obtain them by taking the normal inverse of Eq. (11b) (i.e., $-N^{-1}\left(P_{2}^{H N}\right)$ where $N^{-1}$ is the inverse standard normal distribution function) and Eq. (13b) for the HN GARCH extended Merton model without and with VRP, respectively.
} 


$$
\ln L=\sum_{j=1}^{D}\left\{\sum_{r \in D_{j}}\left[\beta_{1}\left(-D D_{r}\right)+\beta_{2} X_{r}\right]-d_{j} \ln \left[\sum_{r \in R_{j}}\left[\beta_{1}\left(-D D_{j}\right)+\beta_{2} X_{j}\right]\right]\right\}
$$

where $j$ indexes the ordered times of a bank fails $(j=1,2, \cdots, D), D_{j}$ is the set of $d_{j}$ observations that are banks fails at $t(j)$ and $R_{j}$ is the set of observations that are at risk at time $t(j)$. The model allows for censoring in the sense that not all banks failed during the sample period.

The Cox proportional hazard model results given in Table 3 indicate that both default indicators are positive and statistically significant at $1 \%$ significance level. These results suggest that an increase in the default indicators lead to an increase in the hazard ratio. However, of the effects of the estimated distance to default on hazard ratios, the GARCHVRP model has the highest impact compared to the Merton and GARCH models. Overall, the results in Table 3 show that one can improve on the Merton model and the GARCHbased default models with and without VRP are at least as good as the Merton model in forecasting defaults.

To sum up, the model with volatility clustering and variance risk premium features compared to the HN-GARCH option pricing model as well as the KVM-Merton model performs better in the following ways: (1) better tracking of crisis events in the US banking sector; (2) better anticipating the sub-prime crisis and (3) yielding substantially as higher default probabilities as observed during financial turmoil such as the GFC.

\section{Conclusion}

To better-estimate default risk indicators for large US banks, especially in periods of heightened market uncertainty, the paper extended the benchmark structural default risk model to incorporate volatility clustering and variance risk premium effects. Using this rich framework, we show that taking into account these dynamics can improve default risk measures compared to estimates based on standard models. More importantly, concerning model predictive power measures, the model with volatility clustering and variance risk premium produces better performance measures compared to models without such features.

Our analytical and empirical results suggest some directions for further research. First, one could consider endogenous default models along the lines of Leland (2015). Second, alternative GARCH specifications would better capture leverage effects than the HNGARCH model. Third, González-Urteaga and Rubio (2016) find significant cross-sectional variation of volatility risk premia. Finally, a systemic risk analysis for the US financial sector together with the contribution of each bank to the risk can follow up this work.

\section{Appendix A: List of the sampled U.S. Banks}

See Table 4 


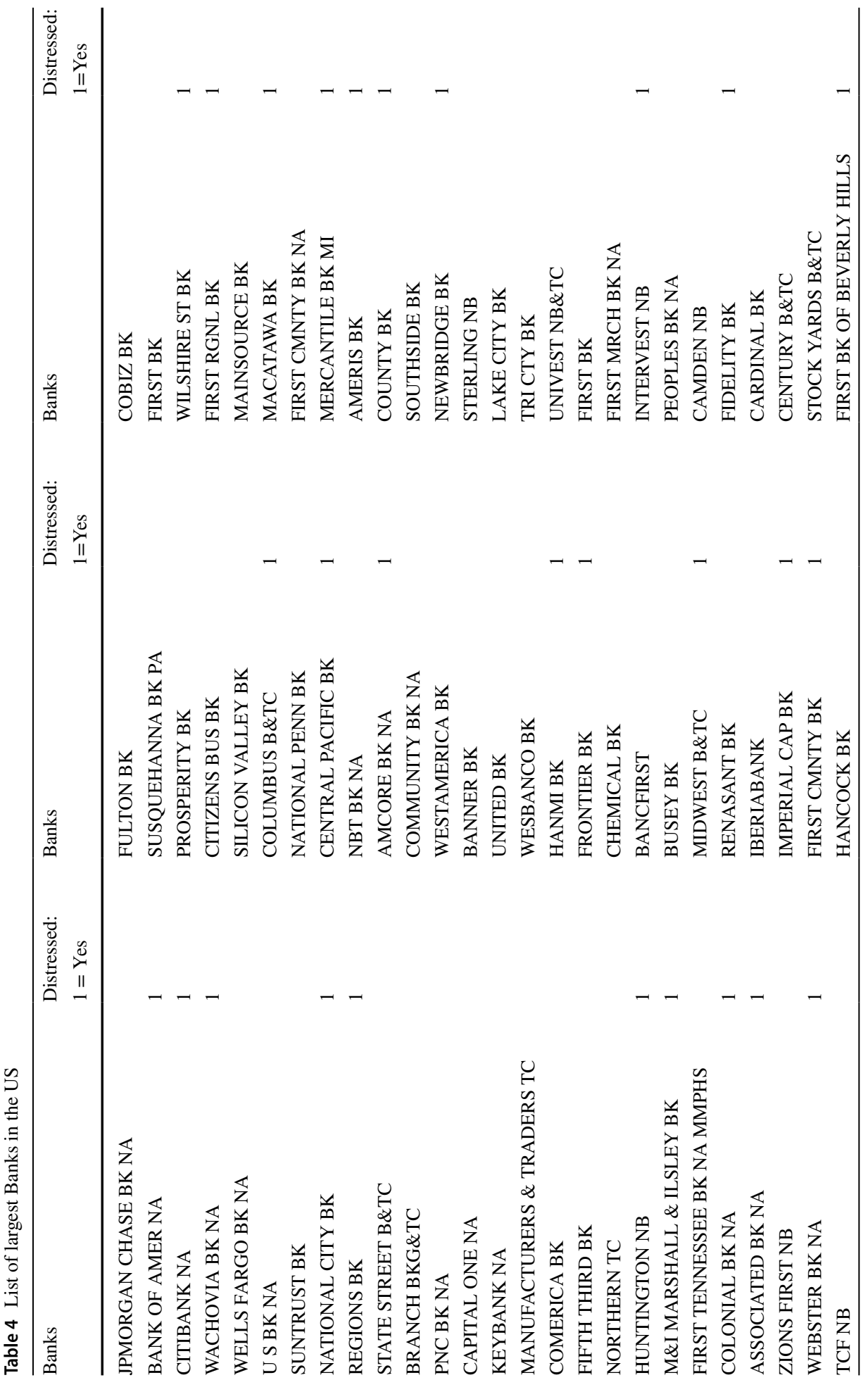




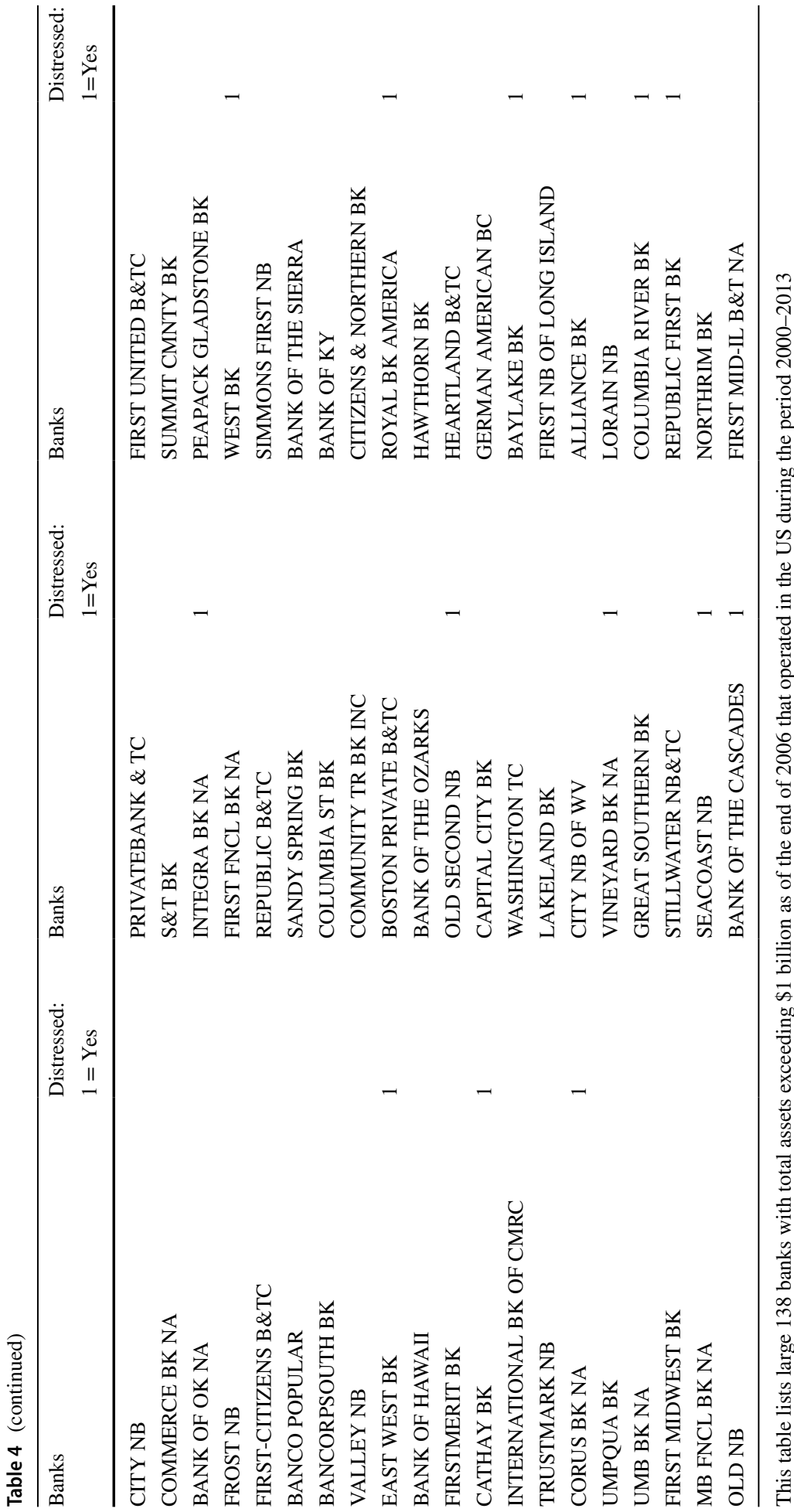




\section{Appendix B: Risk-neutralization of the HN-GARCH with and without variance risk premia}

Following Christoffersen et al. (2013a) and Byun et al. (2015), we use the stochastic discount factor:

$$
\frac{\Lambda_{t}}{\Lambda_{t-1}}=\frac{e^{-v_{1, t} \sqrt{h_{t}} \varepsilon_{t}-v_{2, t} h_{t} \varepsilon_{t}^{2}}}{\mathbf{E}_{t-1}^{\mathbf{P}}\left(e^{-v_{1, t} \sqrt{h_{t}} \varepsilon_{t}-v_{2, t} h_{t} \varepsilon_{t}^{2}}\right)}=e^{v_{1, t} \sqrt{h_{t}} \varepsilon_{t}-v_{2, t} h_{t} \varepsilon_{t}^{2}-\frac{1}{2}\left(\frac{v_{1, t}^{2} h_{t}}{1+2 v_{2, t} h_{t}}-\ln \left(1+2 v_{2, t} h_{t}\right)\right)}
$$

To risk-neutralize the asset value process in Eq. (6), we require

$$
\mathbf{E}^{\mathbf{Q}}\left[e^{\ln \left(A_{t} / A_{t-1}\right)}\right]=\exp \left(r_{t}\right)
$$

To proceed we write:

$$
\begin{aligned}
\mathbf{E}^{\mathbf{Q}}\left[e^{\ln \left(A_{t} / A_{t-1}\right)}\right] & =\mathbf{E}^{\mathbf{P}}\left[\frac{\Lambda_{t}}{\Lambda_{t-1}} e^{\ln \left(A_{t} / A_{t-1}\right)}\right] \\
& =\mathbf{E}^{\mathbf{P}}\left[e^{-v_{1, t} \sqrt{h_{t}} \varepsilon_{t}-v_{2, t} h_{t} \varepsilon_{t}^{2}-\frac{1}{2}\left(\frac{v_{1, t}^{2} h_{t}}{\xi_{t}}-\ln \xi_{t}\right)+r_{t}+\left(\lambda-\frac{1}{2}\right) h_{t}+\sqrt{h_{t}} \varepsilon_{t}}\right] \\
& =e^{r_{t}}
\end{aligned}
$$

where $\xi_{t}=1+2 v_{2, t} h_{t}$. This implies that $v_{1, t}=\lambda$ and $v_{2, t}=(\xi-1) / 2 h_{t}$. The standardized risk-neutral innovation is given by

$$
\varepsilon_{t}^{*}=\sqrt{1-2 \beta_{0} \xi}\left(\varepsilon_{t}+\left(\lambda+\frac{\beta_{0} \xi}{1-2 \beta_{0} \xi}\right) \sqrt{h_{t}}\right)
$$

We repeat the above risk-neutralization process for the case without variance risk premium:

$$
\begin{aligned}
\mathbf{E}^{\mathbf{Q}}\left[e^{\ln \left(A_{t} / A_{t-1}\right)}\right] & =\mathbf{E}^{\mathbf{P}}\left[\frac{\Lambda_{t}}{\Lambda_{t-1}} e^{\ln \left(A_{t} / A_{t-1}\right)}\right] \\
& =\mathbf{E}^{\mathbf{P}}\left[e^{e^{v_{t-1} \varepsilon_{t}}-\frac{1}{2} v_{t-1}^{2}} e^{r_{t}+\left(\lambda-\frac{1}{2}\right) h_{t}+\sqrt{h_{t}} \varepsilon_{t}}\right] \\
& =e^{r_{t}+\lambda h_{t}+v_{t-1} \sqrt{h_{t}} \varepsilon_{t}}=e^{r_{t}},
\end{aligned}
$$

with the implication that $v_{t-1}=-\lambda$ and hence $\varepsilon_{t}^{*}=\varepsilon_{t}+\lambda \sqrt{h_{t}}$ under the risk-neutral-Q measure. We can therefore write the risk-neutral processes for the asset value and variance of its returns as follows:

$$
\begin{gathered}
\ln A_{t}=\ln A_{t-1}+r-\frac{1}{2} h_{t}+\sqrt{h_{t}} \varepsilon_{t}^{*}, \\
h_{t}=\beta_{0}+\beta_{1} h_{t-1}+\beta_{2}\left(\varepsilon_{t-1}^{*}-\gamma^{*} \sqrt{h_{t-1}}\right)^{2},
\end{gathered}
$$

where $\gamma^{*}=\gamma+\lambda$ and $\varepsilon_{t}^{*}=\varepsilon_{t}+\lambda \sqrt{h_{t}}$. 


\section{Appendix C: The characteristic function}

The characteristic function of the HN-GARCH model is represented by a set of difference equations:

$$
f^{*}(t, T ; i \phi)=A^{\phi} \exp \left(M_{t}+N_{t} h_{t+1}\right)
$$

with coefficients

$$
\begin{gathered}
M_{t}=M_{t+1}+\phi r+N_{t+1} \beta_{0}-\frac{1}{2} \ln \left(1-2 \beta_{2} N_{t+1}\right) \\
N_{t}=\phi\left(-\frac{1}{2}+\gamma^{*}\right)--\frac{1}{2} \gamma^{* 2}+\frac{\left(\phi-\gamma^{*}\right)^{2}}{2\left(1-2 N_{t+1} \beta_{2}\right)} \beta_{1} N_{t+1}
\end{gathered}
$$

Note that $M_{t}$ and $N_{t}$ are implicitly functions of $T$ and $\phi$. This system of difference equations can be solved backwards using the terminal condition $M_{T}=N_{T}=0$.

Acknowledgements We thank the late Peter Christoffersen, Lynne Evans, Jens Hagendorff, Thomas Mazzoni, Aydin Ozkan, Martin Sola and seminar participants at the Durham University, the York University, England, the Universidad Torcuato Di Tella, the Korea Development Institute, the Korea Capital Market Institute, the Bank of Korea and the Korean Institute of Finance for useful comments on earlier versions of the paper. Any remaining errors are our responsibility.

\section{Declarations}

Conflict of interest We declare that we have no conflict of interest.

\section{References}

Afik Z, Arad O, Galil K (2016) Using merton model for default prediction: an empirical assessment of selected alternatives. J Empir Finance 35:43-67

Agarwal V, Taffler R (2008) Comparing the performance of market-based and accounting-based bankruptcy prediction models. J Bank Finance 32(8):1541-1551

Babaoglu K, Christoffersen P, Heston S, Jacobs K (2018) Option valuation with volatility components, fat tails, and nonmonotonic pricing kernels. Rev Asset Pricing Stud 8(2):183-231. https://doi.org/ 10.1093/rapstu/rax021

Bakshi G, Kapadia N (2003) Delta-hedged gains and the negative market volatility risk premium. Rev Financl Stud 16(2):527-566. https://doi.org/10.1093/rfs/hhg002

Balachandran S, Kogut B, Harnal H (2010) The probability of default, excessive risk, and executive compensation: a study of financial services firms from 1995 to 2008. Research paper series, Columbia Business School

Bharath ST, Shumway T (2008) Forecasting default with the merton distance to default model. Rev Financ Stud 21(3): 1339-1369

Bollerslev T, Tauchen G, Zhou H (2009) Expected stock returns and variance risk premia. Rev Financ Stud 22(11):4463-4492

Bu D, Liao Y (2014) Corporate credit risk prediction under stochastic volatility and jumps. J Econ Dyn Control 47:263-281. https://doi.org/10.1016/j.jedc.2014.08.006

Byun SJ, Jeon BH, Min B, Yoon SJ (2015) The role of the variance premium in Jump-GARCH option pricing models. J Bank Finance 59:38-56. https://doi.org/10.1016/j.jbankfin.2015.05.009

Câmara A, Popova I, Simkins B (2012) A comparative study of the probability of default for global financial firms. J Bank Finance 36(3):717-732

Campbell JY, Hilscher JD, Szilagyi J (2011) Predicting financial distress and the performance of distressed stocks. J Invest Manag 9(2):14-34 
Carr P, Wu L (2009) Variance risk premiums. Rev Financ Stud 22(3):1311-1341

Choi H, Mueller P, Vedolin A (2017) Bond variance risk premiums*. Rev Finance 21(3):987-1022. https://doi.org/10.1093/rof/rfw072

Christoffersen P, Heston S, Jacobs K (2013a) Capturing option anomalies with a variance-dependent pricing kernel. Rev Financ Stud 26(8):1963-2006. https://doi.org/10.1093/rfs/hht033

Christoffersen P, Jacobs K, Ornthanalai C (2013b) Garch option valuation: theory and evidence. J Deriv 21(2):8-41

Crosbie P, Bohn J (2003) Modeling default risk. White paper, Moody's KMV

Culp CL, Nozawa Y, Veronesi P (2018) Option-based credit spreads. Am Econ Rev 108(2):454-488. https://doi.org/10.1257/aer.20151606

Della Corte P, Ramadorai T, Sarno L (2016) Volatility risk premia and exchange rate predictability. J Financ Econ 120(1):21-40. https://doi.org/10.1016/j.jfineco.2016.02.015

Dew-Becker I, Giglio S, Le A, Rodriguez M (2017) The price of variance risk. J Financ Econ 123(2):225-250. https://doi.org/10.1016/j.jfineco.2016.04.003

Du D, Elkamhi R, Ericsson J (2019) Time-varying asset volatility and the credit spread puzzle. J Finance 74(4):1841-1885. https://doi.org/10.1111/jofi.12765

Duan JC (1994) Maximum likelihood estimation using price data of the derivative contract. Math Finance 4(2):155-167. https://doi.org/10.1111/j.1467-9965.1994.tb00055.x

Duan JC (1995) The garch option pricing model. Math Finance 5(1):13-32

Duan JC (2000) Correction: maximum likelihood estimation using price data of the derivative contract (mathematical finance 1994, 4/2, 155-167). Math Finance 10(4):461-462. https://doi.org/10.1111/ $1467-9965.00105$

Duan JC (2012) Measuring distance-to-default for financial and non-financial firms. Glob Credit Rev 2(95-108):S2010493612500067

Duffie D, Saita L, Wang K (2007) Multi-period corporate default prediction with stochastic covariates. J Financ Econ 83(3):635-665

Engle R, Siriwardane E (2018) Structural garch: the volatility-leverage connection. Rev Financ Stud 31(2):449-492

Glosten LR, Jagannathan R, Runkle DE (1993) On the relation between the expected value and the volatility of the nominal excess return on stocks. J Finance 48(5):1779-1801

González-Urteaga A, Rubio G (2016) The cross-sectional variation of volatility risk premia. J Financ Econ 119(2):353-370. https://doi.org/10.1016/j.jfineco.2015.09.009

Gropp R, Vesala J, Vulpes G (2006) Equity and bond market signals as leading indicators of bank fragility. J Money Credit Bank 38(2):399-428

Gupta J, Gregoriou A, Healy J (2015) Forecasting bankruptcy for SMEs using hazard function: to what extent does size matter? Rev Quant Financ Acc 45(4):845-869. https://doi.org/10.1007/ s11156-014-0458-0

Hao J, Zhang JE (2013) Garch option pricing models, the cboe vix, and variance risk premium. J Financ Econom 3:556-580

Harada K, Ito T, Takahashi S (2010) Is the distance to default a good measure in predicting bank failures? Case studies. Technical report, National Bureau of Economic Research

Heston SL (1993) A closed-form solution for options with stochastic volatility with applications to bond and currency options. Rev Financ Stud 6(2):327-343

Heston SL, Nandi S (2000) A closed-form garch option valuation model. Rev Financ Stud 13(3):585-625

Hillegeist SA, Keating EK, Cram DP, Lundstedt KG (2004) Assessing the probability of bankruptcy. Rev Acc Stud 9(1):5-34

Hsieh KC, Ritchken P (2005) An empirical comparison of garch option pricing models. Rev Deriv Res $8(3): 129-150$

Imerman MB (2020) When enough is not enough: Bank capital and the Too-Big-To-Fail subsidy. Rev Quant Finance Account. https://doi.org/10.1007/s11156-020-00877-x

Jessen C, Lando D (2015) Robustness of distance-to-default. J Bank Finance 50(Supplement C):493505. https://doi.org/10.1016/j.jbankfin.2014.05.016

Kenc T, Cevik EI, Dibooglu S (2021) Bank default indicators with volatility clustering. Ann Finance 17(1):127-151. https://doi.org/10.1007/s10436-020-00369-X

Lehar A (2005) Measuring systemic risk: a risk management approach. J Bank Finance 29(10):2577-2603

Lehar A, Scheicher M, Schittenkopf C (2002) Garch vs. stochastic volatility: option pricing and risk management. J Bank Finance 26(2):323-345

Leland HE (2015) Predictions of default probabilities in structural models of debt. In: Fong HG (ed) The credit market handbook. Wiley, Hoboken, pp 39-64. https://doi.org/10.1002/9781119201892.ch2 
Merton RC (1974) On the pricing of corporate debt: the risk structure of interest rates. J Finance 29(2):449-470

Milne A (2014) Distance to default and the financial crisis. J Financ Stab 12:26-36

Nagel S, Purnanandam A (2019) Banks' risk dynamics and distance to default. Rev Financ Stud. https:// doi.org/10.1093/rfs/hhz125

Papantonis I (2016) Volatility risk premium implications of garch option pricing models. Econ Model 58(Supplement C):104-115. https://doi.org/10.1016/j.econmod.2016.05.004

Prokopczuk M, Symeonidis L, Wese Simen C (2017) Variance risk in commodity markets. J Bank Finance 81:136-149. https://doi.org/10.1016/j.jbankfin.2017.05.003

Saldias M (2013) A market-based approach to sector risk determinants and transmission in the euro area. J Bank Finance 37(11):4534-4555

Vassalou M, Xing Y (2004) Default risk in equity returns. J Finance 59(2):831-868

Wang H, Zhou H, Zhou Y (2013) Credit default swap spreads and variance risk premia. J Bank Finance 37(10):3733-3746. https://doi.org/10.1016/j.jbankfin.2013.02.021

Publisher's Note Springer Nature remains neutral with regard to jurisdictional claims in published maps and institutional affiliations. 